\author{
Dr.C.Adithan' and Dr.B.V.Adkoli ${ }^{2}$ \\ 'Director - CIDRF and Professor of Pharmacology, MGMCRI \\ ${ }^{2}$ Professor \& Head, Department of Health Professions Education
}

MGMCRI, Puducherry - 607403

\section{WHAT IS RESEARCH?}

Medical research is the mother of the evidence based medical practice. We have progressed from empirical therapy based on anecdotal medical knowledge to rational and more scientific therapy. Few diseases like small pox has been eliminated and other diseases like leprosy are under control. This advancement was possible by medical research. Significant contributions for medical research were made not only by qualified medical practitioners and scientists, but also undergraduate students as illustrated by the discovery of insulin by Best and Banting ${ }^{1}$.

\section{MCI VISION DOCUMENT 2015 AND THE NEED FOR RESEARCH IN MBBS COURSE}

It is a common perception that the main objective of a medical student is to obtain a post-graduate degree especially in a clinical discipline. Overwhelming majority of them do not have time or interest in research. They are also ignorant about the potential utility of research in their clinical practice. The MCI Vision document 2015 recognized the need for introducing study of electives among which research methodology has been included as one such subject.. The vision document has emphasized that a doctor should be a life long learner with ability to search data, do a critical appraisal of medical literature in order to tackle a research question. Further the MBBS student should be familiar with basic, clinical and translational research as applied to patient care. A question arises : is it possible to develop such a competency within the frame work of existing curriculum? Perhaps not. We need to therefore look at this issue in a different ways and come out with a multi-pronged approachto develop research competency within the existing framework.

\section{SCENARIO IN WESTERN, ASIAN AND AFRICAN COUNTRIES}

Many medical schools in Western Countries made research as an essential scholarly component during undergraduate (UG) course. In USA, National Institute of Health supports Medical Student Research Fellowship and the Doris Duke Clinical Research Fellowship program ${ }^{2,3}$. Research specific skills are fostered during UG medical course. Some universities have introduced research program of four months duration as a mandatory requirement. ${ }^{4}$ Others expect the UG students to develop, design and implement a primary care project as a part of their curriculum. In many Universities of Canada, Norway and UK, the medical UG students are involved in short term research program ${ }^{5,6}$. In The Netherlands students undertake full time research projects between $4^{\text {th }}$ and $6^{\text {th }}$ year.

It is interesting to note that a few Universities in Bangladesh and Indonesia have incorporated research component in the medical curriculum. In Sri Lanka during the II phase of MBBS curriculum, a dedicated time has been earmarked for data collection and report writing ${ }^{7}$. In Malaysia, the curriculum is community oriented and includeselements of research and evidence based medicine. A study ofmedical education in 30 medical colleges in the Gulf Co-operation Council (GCC) Countries reported that research methods were apart of the curriculum in 10 colleges, and in 7 colleges, it was a separate course. In UAE university, University of Sharjah and Gulf Medical University, research methods are an integral part of UG medical curriculum $^{8,9}$. African medical schools are deficient in research component in their curriculum ${ }^{10}$. 


\section{STATUS AT INDIA}

The undergraduate medical curriculum largely governed by the 1997 MCI Regulations have too little to say on the development of research competency. MCI Vision document 2015 states that research methodology can be included as one of the elective subject. But research is not considered as a formal component of curriculum till now. There are no guidelines available for the medical faculty as to how the research competency can be fostered in the MBBS Course.

A few studies have been published on the status of undergraduate research training in India and the awareness of the faculty or students regarding this critical issue.

Harsha Kumar et al conducted a survey among medical students at Mangalore. According to their findings a vast majority of students whose awareness about research was high were mostly involved in the medical curriculum ${ }^{11}$.

It is interesting to note that the pressure for including research has started coming from the students, the direct consumers of the curriculum. A research paper presented by Reddy et al inthe South East Asian Regional Association for Medical Education, Coimbatore ${ }^{(2012)}$ stated that about $77 \%$ of students favoured inclusion of research training in the MBBS curriculum ${ }^{12}$. There is a positive development among the students and they actively participate in the National Medical Students Research Conference conducted under the banner of After attending 5 such conferences the students have taken a lead and established. Authors had addressed few student national conferences and they found new enthusiasm amongst young medicos to pursue research as a career pathway.
A study by Garg et al expressed concerns regarding the poor state of affair and given some reasons such as lack of mentorship, inadequate infrastructures \& resources and lack of writing skill for biomedical publication ${ }^{13}$. It is essential to address these issues to come out with tangible solutions.

Opportunities availablefor the students to pursue research

There are many opportunities for Indian UG medical students to undertake research during the vacation period (Table 1). Few of them briefly described below.

Short-term Research by Indian Council of Medical Research (ICMR-STS) is very popular program. It calls for proposal in January and provides stipend of Rs. 10000 per month for 2 months. The number of ICMR-STS fellowships are increasing every year. More details are available at the ICMR website (www.icmr. nic.in). National Science Academies such as Indian Academy of Sciences, Bangalore and Indian National Science Academy, New Delhi provides two-month Summer Fellowships to work with scientists in fields of Life Sciences. This is not specific for medical students. Visiting Students' Research Programme offered by Tata Institute (TIFR) also offers opportunity for research in life sciences.

\section{SUGGESTIONS FOR IMPROVING RESEARCH BY UG MEDICAL STUDENTS}

The need for advocacy, sensitization and buy in by the stakeholders: Curricular changes are too slow to happen. They are often riddled with bureaucracy, and often old mind set. Research cant' be left to postgraduate

Table 1. Research opportunities available for undergraduates

- ICMR Short Term Research Studentship : ICMR-STS (1979)

- SUMMER RESEARCH FELLOWSHIP: ( Jawaharlal Nehru Centre for Advanced Scientific Research, Bangalore, www.jncasr.ac.in ), Stipend: Rs. 4000/- per month for 2 months

- SUMMER RESEARCH FELLOWSHIP: Indian Academy Of Science, Bangalore And Indian National Science Academy, India

- KISHORE VAIGYANIK PROTSAHAN YOJNA, Indian Institute Of Science, Bangalore, India. KVPY DST, Govt. of India

- SUMMER FELLOWSHIPS IIT Mumbai VISITING STUDENTS RESEARCH PROGRAM (VSRP) TIFR-Web site: http://www.tifr.res.in/

- Conferences for Medical Students ' MEDICON ' UGCON ' OSMECON ' KARMIC etc 
training alone. The seeds of research and critical enquiry should be sown right from day 1 of a medical education.

Most important requirement for training undergraduate is the availability of trainers, and mentors who can role model, initiate, coach, mentor, handhold and empower the medical students with the tools and techniques for a long term journey. While many medical education centres have introduced workshops training courses at the PG level, it is time to induct UG students in these activities. A dedicated time should be assigned to the PG teachers to mentor each of the UG candidate in the pursuit of a research project that can be funded by the institute or by extra-mural agencies.

The medical colleges should upgrade their library facilities in tune with the emerging requirements such as access to journals, thesis and dissertations, to be made availablefree on $24 \times 7$ basis. With the availability of smart phones and a host of new gadgets, dissemination of resources cannot be a major problem. What is required is the 'will' to do it!

How do we introduce research in to the existing overloaded curriculum? While some experts tend to suggest formal courses during para-clinical phase, others are in favour of integrated approach. Formal courses are difficult to introduce. They may also create 'silos' of learning. Integrated approach is a futuristic trend. The recent development of introducing Attitude and Communication as modules in various phases is a progressive way forward to build research skills too. This step requires a very intensive faculty development program in which the faculty members across the departments sit togetherand design modules linked with their content areas to come out with projects that addresssimple research questions. For example, early exposure of UG students through the community postings can have in-built project in which they can learn about various tools including quantitative and qualitative tools which help them in exploring an issue or describing the same in a real life context. Research skill expected at this level is not as rigorous as expected in the PG level where the emphasis will be laid on explanation, controls and prediction. The elective training in Research Methodology also can't be left alone to the students. It should be accompanied by a mentorship arrangement. The use of e-portfolio comes as a potential instrument for monitoring the progress of the student. A student is expected to record all his/her activities, observations and reflections which are assessed by the mentor with a comprehensivefeedback to help in improvement.

The incentives for the research in terms of institutional support for attending conferences, and incentives for publication in genuinejournals go a long way in encouraging research efforts.

\section{CONCLUSION}

Enriching undergraduate students in research skills is an essential step, if we are serious about the competency of the graduates and postgraduates that we produce from the portals of medical colleges. It is worthwhile to mention that quality assurance and accreditation are essential components for the existenceand survival of academic institutes. Many of the accrediting agencies consider research output as the key performance indicator. If that is to happen, it is imperative that we introduce proactive strategies to foster research skills. This movement requires not only readiness and training of the faculty, but also support from the institutes, amendments from our regulating agencies, and ultimately a culture of recognizing, respecting and rewarding research efforts at all levels of education.

\section{REFERENCES}

1. Stringer MD, Ahmadi O. Famous discoveries by medical students. ANZ J Surg.2009 Dec;79(12):901-8.

2. Solomon SS, Tom SC, Pitchert J, Wasserman D, Powers AC. Impact of medical student research in the development of physician_scientists. J Invest Med 2003; 51 : $149-56$.

3. Gallin EK, Le Blancq SM. Launching a new Fellowship for Medical Students: the first years of the Doris Duke Clinical Research Fellowship Program. J Invest Med 2005; 53: 73-81.

4. Fennimore TF. Structured research activity as a vehicle for fostering reflective Practice among Medical students. JIAMSE 2009; 19 (2S): 7-16

5. Van Eyk HJ, Hooiveld HW, Van Leeuwen TN, Van der Wurff BL, De Craen JM, Dekker FWet al. Scientific output of Dutch medical students. Med Teach. 2010; 32: 231-5

6. Sreedharan J. Introduction of a Research component in the undergraduate medical curriculum - Review of a trend. Nepal J Epidemiol 2012; 2(3):200-204.

7. WHO/SEARO. Review of Preventive and Social Medicine/Community Medicine/ Community Health curriculum for undergraduate medical education. Report of the Expert Group Meeting SEAR0, New Delhi, India. 27-28 August 2009, New Delhi.

8. Abdulrahman KA. The current status of medical education in the Gulf Cooperation council countries. Ann Saudi Med 2008; 28(2): 83-8.

9. Hamdy H, Telmesani AW, Al Wardy N, Abdel-Khalek KN, Carruthers G, Hassan F, et al. Undergraduate medical education in the Gulf Cooperation Council: A multicountries study (Part 1). Medical Teacher 2010; 32: 219-24.

10. Ibrahim A, Asuku ME. Stimulating medical students interest in research: a neglected craft in Africa. Pan Afr Med J. 2012;13:12

11. Harsha Kumar H, Jayaram S, Kumar GS, Vinita J, Rohit S, Satish M, et al. Perception, Practices Towards Research and Predictors ofResearch Career Among UG Medical Students from Coastal South India: ACross-Sectional Study. Indian J Community Med. 2009 0ct;34(4):306-9.

12. Reddy MVR, Khan MS, Goswami, P. Anshu D. How do undergraduate medical students perceive research? Conference Proceedings of "South East Asian Regional Association for Medical Education (SEARAME), Coimbatore" 2012, page 61

13. Garg R, Shobha Goyal S, Singh K. Lack of research amongst undergraduate medical students in India: It's time to act and act now. Indian Pediatr 2017;54: 357-360 